\title{
An attempt of CNC machining cycle's application as a tool of the design feature library elaboration
}

\author{
Cezary Grabowik ${ }^{1}$, Krzysztof Kalinowski ${ }^{1}$, Damian Krenczyk ${ }^{1}$, Iwona Paprocka ${ }^{1}$, \\ and Wojciech Kempa ${ }^{2}$ \\ ${ }^{1}$ Silesian University of Technology, Faculty of Mechanical Engineering, Institute of Engineering \\ Processes Automation and Integrated Manufacturing Systems, Konarskiego 18A, Gliwice, Poland \\ ${ }^{2}$ Silesian University of Technology, The Faculty of Applied Mathematics, Institute of Mathematics, \\ Konarskiego 23A, Gliwice, Poland
}

\begin{abstract}
This paper presents a novel approach to a problem of the design feature library elaboration. As a tool of the design feature library development CNC machining cycles were proposed. Because of the great number of commercially available $\mathrm{CNC}$ machine controllers, with different CNC machining cycles definitions, it was necessary to make a decision about a research methodological framework, it is the selected CNC machine controller. Taking into account the criterion of popularity as the research framework the selected group of Sinumerik CNC machine controllers was chosen. Presented in the paper idea of the feature library development is based on an assumption saying that it is possible to find a relationship between a particular CNC machining cycle and the simple design feature or even compound design features. Identified, thanks to this assumption, set of the design features could be the base for elaboration of the design feature library. This solution, it is the feature library next gave opportunity for elaboration of the feature based design modelling module (FBDMM) working in the SIEMENS NX system environment. Hence, the FBDMM module can support both a designer and CNC machine programmer which is possible due to received in the module modelling paradigm. In FBDMM module the removal feature based modelling technique is received.
\end{abstract}

\section{Methods of the design modelling with design features}

Whilst considering design modelling methods with application of the design feature library, which is implemented in any CAD/CAM/CAE system, it is possible to distinguish the following three modelling methods:

- socalled removal method (technological) which mimics removal manufacturing processes like turning, milling, drilling, reaming and so on. In this method a design is modelled by performing subsequent Boolean's operations, so in each single operation a particular design feature is subtracted from the blank in order to get a finished part model. The schema of modelling process with technological method in the Figure 1a is shown. One of the most important drawbacks of this method is lack of possibilities of 
the design feature library preparing only by means of the design features with a simple design shape structure. In most cases it is needed to work out at least a part of the library with compound design shape features. The biggest advantage of the technological method is its similarity to real manufacturing processes, and it gives possibility of working out a CAPP system with really simple inference mechanism. Well-designed structure of the original modelling module implemented in a $\mathrm{CAD} / \mathrm{CAM} / \mathrm{CAE}$ system environment with the properly worked out a set of the design rules allows to a certain degree to control a design modelling process. Consequently, a designer during the modelling process is supervised in order to follow given modelling standards. In the considered modelling standard the particular design process stages should respond to the subsequent manufacturing process stages. It means that consecutively performed Boolean's operations would respond to certain manufacturing process operations or cuts. As a result, at the first stage of modelling process the "rough" shape of the model, which corresponds to the product stage after roughing, is achieved. At the second stage of modelling process the shaped features of the model are made - the stage after profiling, but taking into consideration that in CAD systems product model is always modelled taking nominal dimensions into account, in principle, after the second modelling stage the final shape of the product is achieved.

- so called additive method (constructional) in opposite to removal modelling method a model design shape come into being as a result of performing of the subsequent unite operations in the sense of the Boolean's operations. A product model is built by adding of the design features together. From manufacturing technology point of view it corresponds to additive manufacturing, in which the product is manufactured with one of the 3D printing - rapid prototyping methods or classic manufacturing technologies like bonding, welding etc. The schema of constructional modelling process in the Figure $1 \mathrm{~b}$ is shown. Like in case of the technological method the biggest drawback of constructional method is necessity of creation of the design features with a compound design shape. This problem can be illustrated by the example of the shaft pin with the splineway manufactured on its surface. In case of the constructional method it would be necessary, at the design feature geometrical shape identification stage, to create a compound shape. As a result, in the considered case it would be the difference between the pin geometrical shape and splineway shape in the sense of the Boolean's operation. As a consequence, it is easy to notice that it is almost impossible to work out the design feature library including all possible combinations of the compound design feature structures.

- so called hybrid method (design-technological), the product model is created by uniting or subtracting particular objects from each other. The schema of modelling process with hybrid method in the Figure 1a is shown. Looking for similarities in the manufacturing realm it corresponds to manufacturing using both removal and bonding manufacturing techniques.

Taking into consideration drawbacks and merits of the particular methods the biggest usefulness in the process of the CAPP system creation shows the first above mentioned method, it is technological modelling method. It comes from fact that this method is in its sense similar to manufacturing processes being realized in real industrial conditions. In addition, as a consequence of deployment of the technological method it would be possible to work out such structure of the CAPP system user interface that the manufacturing process would be designed in the background somewhat.It means that a designer making a design and its design structure would make a process plan, simultaneously. In such case the order of the design features in the design structure would correspond to the order of the manufacturing operations or cuts in the process plan structure. This assumption let us to make the CAPP knowledge based system with simple inference mechanism. Consequently, 
the inference mechanism is built of a set of inference rules that interlink a certain design feature with strictly ascribed manufacturing feature. Despite unquestionable advantages of such solution its effectiveness is in principle limited to a group of products such as shafts, sleeves and disks.

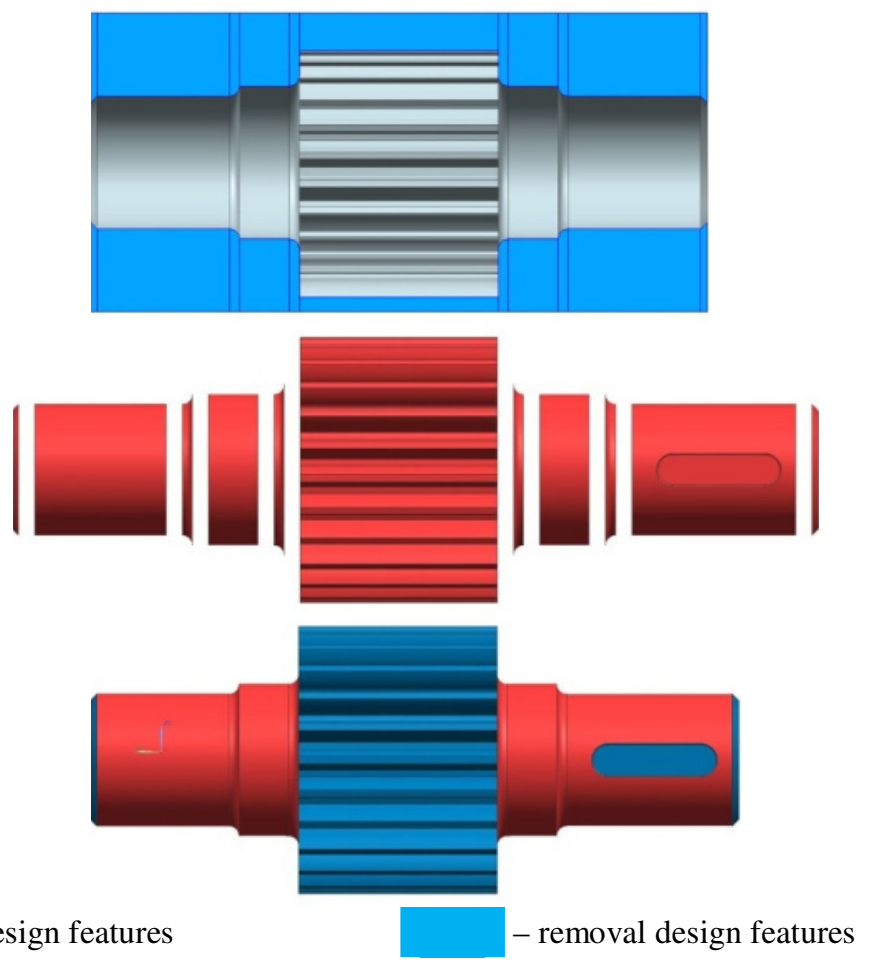

Fig. 1. Design modelling methods with design features, a) removal, b) additive, c) hybrid.

\section{Machining cycles as base for the design feature library elaboration}

Machining cycles are commonly considered as the important element of CNC control programmes. They allow to automise the CNC programming process, and they also limit the programmes size. Thanks to them it is possible to change manufacturing parameters in an easy and quick way. The concept of machining cycle is understood as a constant parameterized subprogram stored in the control system memory used for programming typical manufacturing operations such as turning, drilling, milling, threading etc.

Machining cycles programming process is very often supported by the dialog programming module like in case of Sinumerik control system. In such case a CNC programmer is visually assisted in order to make them familiar with the particular machining cycle parameters and their permissible values [5-6]. Taking into account they characteristic the machining cycles can be roughly grouped in to the three groups it is: (i) drilling cycles, (ii) milling cycles and (iii) turning cycles. As it was mentioned in the abstract paragraph because of the great number of commercially available CNC machine controllers, with different $\mathrm{CNC}$ machining cycles definitions, it was necessary to make a decision about a research methodological framework, it is the selected CNC machine controllers group. Taking into account the criterion of popularity,in the considered case in Polish industry conditions, as the research framework the selected group of Sinumerik CNC machine controllers was chosen. Although, presented in the paper result can be generalized 
for other CNC machine controllers like these offered by Fanuc, Heidenhain or Okuma producers. In our work we were focused on the group of Sinumerik 810D, 840D and 840Di CNC controllers. The idea of the feature library development is based on a general assumption saying that it is possible to find a relationship between a particular CNC machining cycle and the simple design feature or a compound design features.

\subsection{An overview of the machining cycles for Sinumerik 810D/840D/840Di}

From definition machining cycles are motion sequences defined for drilling, boring/reaming, tapping etc. according to standard DIN 66025. These machining cycles are called in the form of subroutine with the unique cycle name and appropriate set of the parameters. In Sinumerik 810D/840D/840Di control systems there are five drilling and five boring/reaming machining cycles available. The short description of these cycles in the Table 1 is given [1,2].

Table 1.Drilling and boring machining cycles in Sinumerik 810D/840D/840Di [1].

\begin{tabular}{|c|c|c|}
\hline Machining cycle type & Cycle name & Cycle function and description \\
\hline Drilling, centering & CYCLE81 & $\begin{array}{l}\text { The tool drills at the programmed spindle speed and } \\
\text { federate to the programmed final drilling depth. }\end{array}$ \\
\hline Drilling, counterboring & CYCLE82 & $\begin{array}{l}\text { The tool drills at the programmed spindle speed and } \\
\text { federate to the programmed final drilling depth. A dwell } \\
\text { time can be allowed to elapse when the final drilling } \\
\text { depth has been reached. }\end{array}$ \\
\hline Deep-hole drilling & CYCLE83 & $\begin{array}{l}\text { The tool drills at the programmed spindle speed and } \\
\text { federate to the programmed final drilling depth. } \\
\text { Operation is performed with a depth infeed of a } \\
\text { maximum definable depth executed several times. The } \\
\text { tool can be retracted in order to swarf remove or for chip } \\
\text { breaking. }\end{array}$ \\
\hline Rigid tapping & CYCLE84 & $\begin{array}{l}\text { Rigid tapping with programmed spindle speed and } \\
\text { federate to the programmed thread depth. }\end{array}$ \\
\hline $\begin{array}{l}\text { Tapping with } \\
\text { compensation chuck }\end{array}$ & CYCLE840 & $\begin{array}{l}\text { Taping with compensation chuck operation with } \\
\text { programmed spindle speed and federate to the } \\
\text { programmed thread depth. }\end{array}$ \\
\hline Boring 1 & CYCLE85 & Different feedrates for boring and retraction. \\
\hline Boring 2 & CYCLE86 & $\begin{array}{l}\text { Oriented spindle stop, definition of retraction path, } \\
\text { retraction in rapid traverse, definition spindle direction of } \\
\text { rotation. }\end{array}$ \\
\hline Boring 3 & CYCLE87 & $\begin{array}{l}\text { Spindle stops M5 and program stop M10 at drilling } \\
\text { depth, continued machining after NC Start in rapid } \\
\text { reverse, definition of spindle direction of rotation. }\end{array}$ \\
\hline Boring 4 & CYCLE88 & As for CYCLE87 plus dwell time at drilling depth \\
\hline Boring 5 & CYCLE89 & Boring and retraction at the same speed. \\
\hline Row holes & HOLES1 & $\begin{array}{l}\text { Drilling of a row holes i.e. a number of holes that lie } \\
\text { along a straight line or a grid of holes. }\end{array}$ \\
\hline Hole circle & HOLES2 & $\begin{array}{l}\text { Drilling a circle of holes. The type of holes must be } \\
\text { determined by the drilling cycle. }\end{array}$ \\
\hline
\end{tabular}

Turning cycles in most $\mathrm{CNC}$ machine controllers are used for programming of the following manufacturing cuts: turning, boring, grooving, threading or manufacturing undercuts. In addition, there are some hole manufacturing cycles in Sinumerik 
810D/840D/840Di control systems. They are derived from above mentioned boring/reaming cycles excluding specific milling manufacturing cycles for example machining of the holes patterns. There are seven turning machining cycles available in Sinumerik 810D/840D/840Di control systems. The short description of these cycles in the Table 2 is given.

Table 2.Turning machining cycles in Sinumerik 810D/840D/840Di [1].

\begin{tabular}{|l|l|l|}
\hline Machining cycle type & Cycle name & \multicolumn{1}{c|}{ Cycle function and description } \\
\hline Grooving & CYCLE93 & $\begin{array}{l}\text { Turning of symmetrical and asymmetrical groves for } \\
\text { longitudinal and travers machining on straight contour } \\
\text { elements. }\end{array}$ \\
\hline Undercut & CYCLE94 & $\begin{array}{l}\text { Machining of undercuts of E and F forms in accordance } \\
\text { with DIN509 with the usual load on a finished part. }\end{array}$ \\
\hline Stock removal & $\begin{array}{l}\text { With this cycle, contours can be machined in the } \\
\text { longitudinal and facing directions, inside and outside. } \\
\text { This cycle is freely selectable for roughing, finishing, } \\
\text { complete machining). }\end{array}$ \\
\hline Thread undercut & CYCLE96 & $\begin{array}{l}\text { Cycle used for thread undercuts machining of A, B, C, } \\
\text { and D forms in accordance with DIN 76 on parts with a } \\
\text { metric ISO thread. }\end{array}$ \\
\hline Thread cutting & CYCLE98 & $\begin{array}{l}\text { Turning of threads. } \\
\text { It allows to produce several concatenated cylindrical or } \\
\text { tapered threads with constant lead in longitudinal or face } \\
\text { machining, all of which can have different thread loads. }\end{array}$ \\
\hline Extended stock removal & CYCLE950 & $\begin{array}{l}\text { The same as for CYCLE95, but the finished part contour } \\
\text { profile cannot have any relief cuts must be continuous. } \\
\text { For roughing the programmed infeed is set precisely, the } \\
\text { last two roughing steps are divided equally. Roughing it } \\
\text { performed to the programmed to final machining } \\
\text { allowance. Finishing is performed in the same direction } \\
\text { as roughing. }\end{array}$ \\
\hline
\end{tabular}

Because, at the current stage of our research we are focued only on rotational symmetric parts such as shafts, sleeves and shilds, the machining cycles analisis was limited to gruops of boring/reaming and turning cycles. The analisys of the usebillity of milling cycles for design features identification was omitted. Taking into account the set of available machining cycles, in the consiedered case these of the Sinumerik 810D/840D/840Di machine contollers it can be stated that is possible to work out a set of the desing features that can be next treated as the base for feature based design modelling module elaboration.

In the Figure 2 aproposed structure of design feature classes worked out on the basis of the usuablity of the machine cycles is shown. It could be easily noticed thatthis structure is strictly oriented on machining cycles. Moreover, the characteristic feature of it is its simplicity compere to other structures for example presented in [3]. This simplicity results from fact that the internal structure of the particulars classes is more complex than in case of the complex class structures but with less complex structures of the classes. The base class in the proposed solution is Design class that represents the product itself. The rest of classes are derived from this class. Design features such as pins - cylindrical, conical and profile external surfaces are represented by object of the Profile class. Holes both circumferential and travers are represented by instances of the Drilling class and its derivative classes it is Centering, HoleDrilling, DeepHoleDrilling, Counterboring, and Boring classes respectively. Design features of threads by means of the Tapping, Thread class, and their derivative classes are represented in the model, whilst undercuts by the Undercut class and its derivative classes such as UndercutFormE, and UndercutFormF 


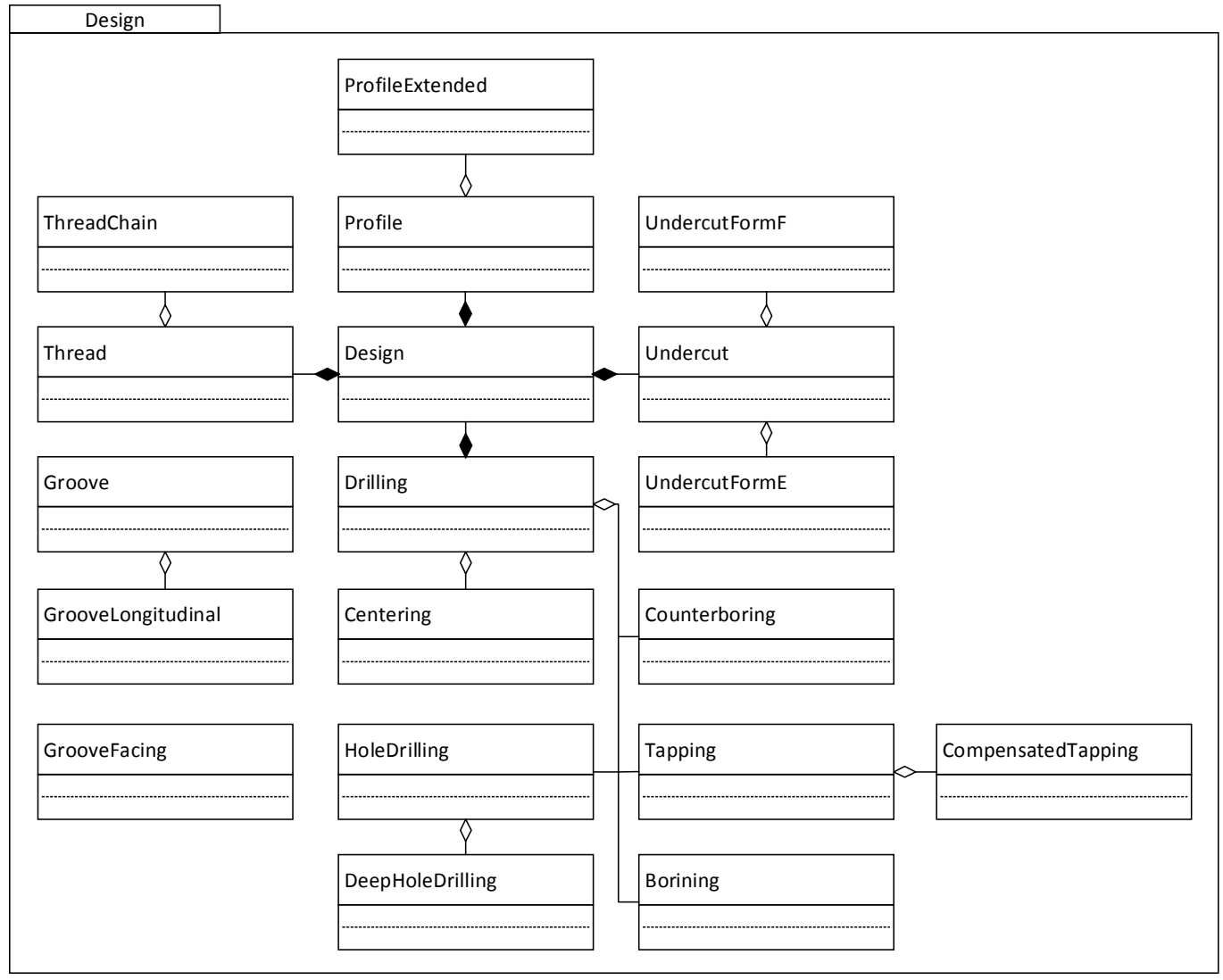

Fig. 2. The proposed structure of the design features.

classes. Grooves in the design features class structure are represented by the Groove class and its derivative classes GrooveLongitudinal, and GrooveFacing.

\section{Conclusions}

In the paper an attempt of application of the machining cycles in order to build the design feature library is presented. At the current state of the research the proposed structure of the design features is strictly oriented on manufacturing operations that can be performed with a lathe and milling machines equipped with Sinumerik 810D/840D/840Di CNC controller, but the achieved result are promising enough to say that they can be applied for any other CNC controller. This result will be used for creating of the prototype of the CAPP system.

\section{References}

1. Siemens, Sinumerik 840D/840Di/810D/FM-MC programming guide (Siemens, 2000)

2. C. Grabowik, K. Kalinowski, D. Krenczyk, Lect. note. in arti. inte. 7209 (2012)

3. A. Kampa, G. Gołda, I. Paprocka, Comp. 6, 10 (2017), doi:10.3390/computers6010010

4. A. Gwiazda, R. Knosala, J. of Mat. Proc. Technol. 64 1-3 (1997) doi: doi:10.1016/S0924-0136(96)02566-6

5. A. Gwiazda, W. Banaś, A. Sękala, K. Foit, P. Hryniewicz, G. Kost, IOP Conf. Ser. Mater. Sci. Eng. 95 (2015) doi:10.1088/1757-899X/95/1/012104

6. K. Foit, A. Gwiazda, W. Banas, A. Sekala, P. Hryniewicz, IOP Conf. Ser. Mater. Sci. Eng. 95 (2015) doi: 10.1088/1757-899X/95/1/01210 